\title{
MASS AND ENERGY-CAPITAL CONSERVATION EQUATIONS TO FORECAST THE MONTHLY OIL PRICE
}

\section{Fabio Gori}

University of Rome "Tor Vergata", Via del Politecnico 1, 00133 Rome, Italy

Fax+39-06-2021351, E-mail: fammannati@yahoo.com

\begin{abstract}
Mass and the energy-capital conservation equations are employed to study the time evolution of the mass of oil and the oil price evolution with time of the resources sold to the market in case of noaccumulation and no-depletion of the resources; i.e. when the resources are extracted and sold to the market at the same mass flow rate. The time evolution of the monthly oil price is studied from 1994 until 2012, investigating the detailed forecast resulting from the application of the present theory. The oil price can be reasonably forecasted using the prime and the discount rate interests as extreme limits.
\end{abstract}

Keywords: Oil price; Monthly forecast, Mass and energy-capital conservation equations.

\section{NOMENCLATURE}

Latin

$G_{k}=G p r \quad$ capital flow rate

$G \quad$ mass flow rate

$K=G p \quad$ capital flow

$M \quad$ mass

p price

$p^{*}{ }_{S O}=r_{N} p_{E 0} /\left(r_{E}-r_{N}\right) \quad$ critical initial price of sold resources, CIPS

$p^{* *}{ }_{S O}=r_{N} p_{E 0} / \beta, \quad$ critical initial extreme price of sold resources, CIPES

$r$ interest rate $\left(\right.$ annum $\left.^{-1}\right)$

$t$ time

Greek

$\alpha=\frac{1}{G} \frac{d G}{d t} \quad$ extraction rate

$\beta=r_{N}-\alpha \quad$ price-increase factor of extracted resources, PIFE

$\beta^{\prime}=r_{E}-\alpha \quad$ price-increase factor of sold resources, PIFS.

Subscript

0

initial

E extracted resources

$f$

final 


$\begin{array}{ll}k & \text { capital } \\ m & \text { maximum or minimum } \\ \max & \text { maximum } \\ \min & \text { minimum } \\ N & \text { non-extracted resources } \\ o & \text { initial } \\ S & \text { sold resources }\end{array}$

\section{INTRODUCTION}

The forecast of the price of non-renewable resources is very important in the economic planning. The main economic issues related to an economy based on exhaustible resources has been investigated in [1] and later reviewed in [2]. Hotelling rule suggest that the price of non-renewable energy resources increases exponentially with the product of time and interest rate of capital, [1-2].

A first generalization of the Hotelling rule, [3], has shown that the rate of exponential increase can be interpreted as the product of the time and the difference between the inflation rate and the extraction rate, called PIFE, i.e. "Price Increase Factor of Extracted resources". A further generalization of the Hotelling rule, [4], has introduced the difference between the interest rate of the capital, prime or discount rate, and the extraction rate, called PIFS, i.e. "Price Increase Factor of Sold resources". The price of a sold resource can increase or decrease with time, also passing throughout a maximum or a minimum [3-4], differently from what happens with the Hotelling rule, where the price is linked only to the interest rate of the capital, which usually is positive.

The energy supply curve of non-renewable energy resources, i.e. price versus consumption, can be constructed introducing new parameters of evaluation, [5]. The real annual mass flow rate of oil extraction in the world from 1965 to 2006 has been presented in [6], according to the data of [7].

The same approach has been recently applied to periods with negative inflation rates, confirming the robustness of the present theory and identifying the limits of the forecast in the assumption of the interest rates, e.g. prime or discount rates. The preliminary results of [8] are confirmed in [9] for a more wide variation of the discount rates, showing the importance of the two new parameters, CIPS, "Critical Initial Price of Sold resources", which depends on the initial price of the extracted resources, on the interest rate of the non-extracted resources, and the difference between PIFS and PIFE, and CIPES, "Critical Initial Price Extreme of Sold resources", which depends on the initial price of the extracted resources, on the interest rate of the non-extracted resources, and PIFS. 
The present paper applies the approach to the forecast of the monthly oil price during the period from 1994 to October 2012, discussing the use of the real interest rates, as limits of the forecast.

\section{MASS CONSERVATION EQUATION OF EXTRACTED RESOURCES.}

Let assume that the non-extracted resource is in a reservoir $\mathrm{C}_{\mathrm{N}}$ of mass, $M$, where $M_{0}$ is the mass at the initial time, $t=0$. If the mass flow rate of extraction is $G$, with dimensions (mass/annum), the mass conservation equation of the non-extracted resource is

$$
\frac{d M}{d t}=-G
$$

If the extraction rate, $\alpha$, with dimensions (\%/annum), is

$$
\frac{1}{G} \frac{d G}{d t}=\alpha
$$

the mass flow rate of extraction, with constant $\alpha$ in the time interval $0-t$, is

$$
G=G_{0} \exp (\alpha t)
$$

The evolution of the mass flow rate of extraction with time depends on the value of $\alpha$. If $\alpha=0$, $G$ is constant with time. If $\alpha>0, G$ increases with time. If $\alpha<0, G$ decreases with time.

\section{Annual balance}

The annual mass flow rate of oil extraction in the world, $G$, is reported from 1965 until 2012 in Fig. 1, according to the data of [7], and from 1980 until 2012 according to [10].

From 1965 until 1973 a continuous increase of $G$ was present. From 1973 to 1975 the mass flow rate decreased but, from 1975 until 1979, a new increase was present with a trend similar to that of the period 1965-1973. From 1979 to 1983 the mass flow rate decreased while it was constant from 1983 until 1985. From 1985 until 2004 the mass flow rate has continuously increased, with the exception of the years 1999, 2001 and 2002. From 2004 to 2009 the mass flow rate was almost constant, while from 2009 it is increasing. A similar picture can be obtained from the data of [10], from 1980 until 2012, which are quite similar, despite some slight differences during the last few years.

The mass of oil in the reservoir of non-extracted resources, $\mathrm{C}_{\mathrm{N}}$, Eq. 1, becomes, after integration

$M=M_{0}+G_{0}[1-\exp (\alpha t)] / \alpha$

For constant extraction rate, $G=G_{0}$, i.e. $\alpha=0$, mass of resources is

$M=M_{o}-G_{o} t$

Then, $M$ decreases linearly with time and is possible to find the time $t_{f}=M_{0} / G_{0}$ when $M=0$, i.e. the exhaustion of non-extracted resources [3]. 
If $\alpha>0$, mass of resources is exhausted faster than for $\alpha=0$, while if $\alpha<0$, mass of resources is exhausted slower than for $\alpha=0$ [3]. For an infinite time $t \rightarrow \infty$, the mass of resources in the reservoir is given by, under the assumption of a negative value of $\alpha$,

$$
M(\infty)=M_{o}-\frac{G_{o}}{|\alpha|}
$$

An extraction policy is able to exhaust the non-renewable resources in an infinite time $t \rightarrow \infty$, i.e. $M(\infty)=0$, giving the critical extraction rate, $\alpha_{c}$, [3]

$$
\left|\alpha_{c}\right|=\frac{G_{o}}{M_{o}}
$$

If $\alpha<\alpha_{c}<0$ the non-renewable resources will never be extracted and a certain amount of resources will remain as non-extracted in the reservoir $\mathrm{C}_{\mathrm{N}}$, [3].

The real annual extraction rates, $\alpha$, evaluated using the data of [7] for two successive years, are reported in Fig. 2 from 1966 until 2011, along to the extraction rates, $\alpha$, evaluated using the data of [10], which are available from 1981 until 2011.

The extraction rates obtained from [7] oscillated around 8 (\%/annum) from 1966 to 1976 with a minimum below -5 (\%/annum) in 1975. From 1977 until 2008 the extraction rates oscillated between 5 (\%/annum) and -5 (\%/annum) with the exception of 1981, when decreased below -5 (\%/annum). From 2006 extraction rate is oscillating around zero. As a conclusion, the real annual extraction rates, $\alpha$, decreased from the high values of the 60 's down to values around $-5 \%$ in special years of oil crisis, as 1975,1981 , while from the 80 's the real annual extraction rate, $\alpha$, is oscillating within a smaller range. The extraction rates obtained from [10] are oscillating with smaller variations, but the general trend is similar.

Figure 2 compares also the real annual extraction rates, $\alpha$, with the critical extraction rates, $\alpha_{c}$, showing that $\alpha_{c}$ has been stable around $-4 \%$ from the 80 's, when the real annual extraction rate is greater than the critical extraction rate, $\alpha_{c}$, except during the years of economic crisis, as 1999 and 2009, when they are almost equal.

The evolution of the proved reserves of oil in the world during the period 1980-2011 is reported in Fig. 3 according to the data of [7] and [10]. Despite the difference, they seems to have the same trend. An increase of the oil reserves in the world is observed from 1980, with a double value between 1998 and 1999 according to [7] and between 2002 and 2003 according to [10]. The data of [7] from 2007 up to 2011 show the trend to become three times the reserves of 1980, i.e. towards 240,000 MT.

The ratio $M / G$ of oil in the world gives the years remaining for the non-renewable resource oil. The ratio $M / G$ is reported in Fig. 4 from 1980 until 2011 according to [7,10] with some 
differences between the two sources of data. The starting point was around 30 years in 1980 and it has increased up to around 45 years in the 90's, 50 years in the 2000's and it has overcome 55 years in 2010, according to [7]. The years are somewhat lower according to [10], remaining below 50 years in 2010 .

\section{Monthly balance}

The monthly extraction rates are reported from January 1994 until October of 2012 in Fig. 5, according to the data of [10]. The unit of $G$ is $M T / y$ in order to be comparable to the data of Fig. 1 . The increase is continuous.

\section{ENERGY-CAPITAL CONSERVATION EQUATION OF EXTRACTED RESOURCES}

Hotelling rule, so called in [1] in honour of H. Hotelling [2], states that the price of a nonrenewable resource increases exponentially with the time multiplied the interest rate $r$ of capital and is independent of any other variable present in the energy game of the non-renewable resources.

The evolution of the oil price (West Texas Intermediate) is reported in Fig. 6 as monthly average [11] from January 1994 until the October 2012, with the dimensions of US\$ of the day per unit of Giga Joule (US\$day/GJ). The evolution of the oil price is very well know and is not necessary to make further comments. It can only be remarked the oscillations of the last few years, within a general trend to increase from 2009.

The interest rates taken into account in the present paper are discount, prime, [11], and inflation rates [12]. Monthly inflation rates are reported together to the monthly oil price in Fig. 6 from January 1994 until December 2012. From 1994 until 1997 the oil price is coupled to the inflation variation, either when the price decreases than when it increases. From 1997 until 2003 the price variations are stronger than the inflation ones. From 2003 until 2007 the divergence between oil price and inflation has increased, because oil price has continuously increased up to a maximum around the middle of 2006, while inflation remained within the limit of $+5 \%$. The sharp increase of the oil price from 2007 until the middle of 2008 is not related to the inflation rate which is greater than $5 \%$ only during few months of 2008 . The sharp decrease of the oil price from the middle of 2008 until the beginning of 2009 is somewhat related to the decrease of the inflation rate which became null at the beginning of 2009. From the beginning of 2009 until the middle of 2009 it is observed a divergence of the two trends because the monthly price has increased while inflation has become negative. From the middle of 2009 the inflation has increased again but, until October 2012 it has remained well below 4\% while the oil price has increased, with some oscillations, until 2013.

Energy-capital conservation equation for the extracted resources is, in unsteady state [3] $d\left(G p_{E}\right) /(d t)=G p_{E} r_{N}$ 
where $G$ is the mass flow rate of extraction, $p_{E}$ the current price of a unity of extracted resource and $r_{N}$ the interest rate. Equation 8 becomes the Hotelling rule for $G=1$.

Equation 2, gives, after integration, the price evolution of the extracted resource, with interest rate $r_{N}$

$p_{E}=p_{E 0} \exp (\beta t)$

where $p_{E 0}$ is the initial price of the extracted resource and

$\beta=r_{N}-\alpha$,

is the "Price Increase Factor of Extracted resources", PIFE.

As a conclusion, the price of the extracted resources evolves with time according to PIFE. If the extraction rate $\alpha$ is equal to the interest rate of the non-extracted resource, $r_{N}$, the price-increase factor, $P I F E$, is equal to zero, $\beta=0$, and the price $p_{E}$ remains constant with time. If the extraction rate $\alpha$ is higher than $r_{N}$, the price-increase factor, PIFE, is negative, $\beta<0$, and the price $p_{E}$ decreases with time. If the extraction rate $\alpha$, is lower than $r_{N}$, the price-increase factor, PIFE, is positive, $\beta>0$, and the price $p_{E}$ increases with time. In case of a conservative policy of extraction, i.e. $\alpha<0$, the price-increase factor is greater than zero, $\beta>0$ and the price $p_{E}$ increases with time.

\section{ENERGY-CAPITAL CONSERVATION EQUATION OF SOLD RESOURCES}

Let assume that the non-extracted resources are in a reservoir $\mathrm{C}_{\mathrm{N}}$ with mass $M_{N}$ and interest rate $r_{N}$. Mass flow rate of extraction from reservoir $\mathrm{C}_{\mathrm{N}}$ is $G_{E}$ while capital flow rate, relative to the mass flow rate $G_{E}$, is $G_{E} p_{E}$, because resources are extracted at the price, $p_{E}$, and allocated in the reservoir $\mathrm{C}_{\mathrm{E}}$, where $M_{E}$ is the mass of extracted resources. Resources of the reservoir $\mathrm{C}_{\mathrm{E}}$ are sold at the price $p_{S}$, with a mass flow rate of extraction $G_{S}$, while capital flow rate, relative to the mass flow rate $G_{S}$, is $G_{S} p_{S}$.

Mass conservation equation of the resources in the reservoir $\mathrm{C}_{\mathrm{E}}$ is

$\frac{d M_{E}}{d t}=G_{E}-G_{S}$

Energy-capital conservation equation is

$$
\frac{d}{d t}\left(G_{S} \cdot p_{S}\right)=G_{S} \cdot p_{S} \cdot r_{E}-G_{E} \cdot p_{E} \cdot r_{N}
$$

which becomes

$$
\frac{1}{p_{S}} \cdot \frac{d p_{S}}{d t}+\frac{1}{G_{S}} \cdot \frac{d G_{S}}{d t}=r_{E}-\frac{G_{E} \cdot p_{E}}{G_{S} \cdot p_{S}} \cdot r_{N}
$$

In case of no-accumulation and no-depletion of the extracted resources in the reservoir $\mathrm{C}_{\mathrm{E}}$, i.e. $G_{E}=G_{S}$, mass $M_{E}$ is constant with time and mass flow rates $G_{E}$ and $G_{S}$ have the same extraction rate $\alpha$ 
$G_{E}=G_{S}=G_{E o} \cdot \exp (\alpha t)=G_{S o} \cdot \exp (\alpha t)$

Equation (13) becomes, with Eq. (14),

$\frac{d p_{S}}{d t}=p_{S}\left(r_{E}-\alpha\right)-p_{E} \cdot r_{N}$

Solution of Eq. (15) for $r_{E} \neq r_{N}$, [13], gives the time evolution of the price of sold resources

$p_{S}=p^{*}{ }_{s 0} \exp (\beta t)+\left[p_{S 0}-p^{*}{ }_{S 0}\right] \exp \left(\beta^{\prime} t\right)$

where $p_{S 0}$ is the initial price of the selling resource,

$\beta^{\prime}=r_{E}-\alpha$

is the "Price Increase Factor of Sold resources", PIFS, and

$p^{*}{ }_{S 0}=r_{N} p_{E 0} /\left(\beta^{\prime}-\beta\right)$

is the "Critical Initial Price of Sold resources", CIPS, which depends on $p_{E 0}$, the initial price of the extracted resource.

Price of sold resources, Eq. 16, has an extreme (maximum or minimum) for time $t_{m}$

$t_{m}=1 /\left(\beta-\beta^{\prime}\right) \ln \left(\beta^{\prime}\left(p^{*}{ }_{S 0}-p_{S O}\right) / \beta / p^{*}{ }_{S 0}\right)$

Time $t_{m}$ of the extreme is zero if $p_{S 0}$ is equal to

$p^{* *}{ }_{S 0}=r_{N} p_{E 0} / \beta$,

which is the "Critical Initial Price Extreme of Sold resources", CIPES, which depends on $p_{E 0}$, the initial price of the extracted resource.

For $r_{N}=r_{E}$, i.e. $\beta^{\prime}=\beta$, $p_{S}$ is given by

$p_{S}=\left(p_{S 0}-p^{* *}{ }_{S 0} \beta t\right) \exp (\beta t)$

where CIPS, i.e. $p^{*}$ so, is not defined.

The price of sold resources has an extreme for the time $t_{m}$ given by

$t_{m}=\left(p_{S O}-p^{* *}{ }_{S O}\right) / p^{* *}{ }_{S O} / \beta$,

The extreme is a maximum if $p^{* *}{ }_{S O}>0$ and a minimum if $p^{* *}{ }_{S 0}<0$. The time $t_{m}$ of the maximum is zero if the initial price $p_{S O}$ is

$p_{S 0}=p^{* *}{ }_{S 0}=r_{N} p_{E 0} / \beta^{\prime}$

The possible cases can be classified in five categories:

- $\quad$ Cat. $1-r_{N}>\alpha$, i.e. $\beta=P I F E>0$.

- $\quad$ Cat. $2-\alpha>r_{N}$, i.e. $\beta=P I F E<0$.

- $\quad$ Cat. $3-\alpha=r_{N}$, i.e. $\beta=P I F E=0$.

- Cat. $4-r_{N}=r_{E}$, i.e. $\beta^{\prime}=\beta$ or PIFE $=$ PIFS.

- Cat. $5-r_{N}<0$.

On their side, each category presents the following possible cases: 
Category $1-r_{N}>\alpha$, i.e. $\beta=P I F E>0$.

- Case 1-A) $r_{E}>r_{N}>\alpha$, i.e. $\beta>\beta>0$.

The price of the selling resource increases with time if the initial price $p_{S 0}$ is $p_{S O} \geq p_{S O}^{*} p^{* *}>0$, i.e. greater or equal than $C I P S>C I P E S>0$.

- Case 1-B) $r_{E}>r_{N}>\alpha$, i.e. $\beta^{\prime}>\beta>0$, or $r_{N}>r_{E}>\alpha$, i.e. $\beta>\beta^{\prime}>0$.

The price of the selling resource increases temporarily with time up to $t_{m}$, given by Eq. (19), and then decreases: for $r_{E}>r_{N}>\alpha$ if the initial price $p_{S O}$ has a value comprised between CIPS and CIPES, i.e. $p^{*}{ }_{S 0}>p_{S 0}>p^{* *}{ }_{S 0}>0$, or, for $r_{N}>r_{E}>\alpha$, if the initial price $p_{S 0}$ is greater than CIPES, i.e. $p_{S O}>p * *_{S O}>0>p{ }^{*}{ }_{S O}$.

- Case 1-C) $r_{E}>r_{N}>\alpha$, i.e. $\beta^{\prime}>\beta>0$, or $r_{N}>r_{E}>\alpha$, i.e. $\beta>\beta^{\prime}>0$, or $r_{N}>\alpha>r_{E}$, i.e. $\beta>0>\beta$ '.

The price of the selling resource decreases with time: for $r_{E}>r_{N}>\alpha$ if the initial price $p_{S 0}$ is smaller than CIPS and CIPES, i.e. $p^{*}{ }_{S 0}>p^{* *}{ }_{S O}>p_{S 0}$, or, for $r_{N}>r_{E}>\alpha$, if the initial price $p_{S 0}$ is smaller than CIPES, i.e. $p^{* *}{ }_{S O}>p_{S O}>0>p^{*}{ }_{S O}$, or, for $r_{N}>\alpha>r_{E}$ for every initial price $p_{S O}$ because $p_{S 0}>0>p^{*}{ }_{S 0}>p{ }^{* *}{ }_{S 0}$

Category $2-\alpha>r_{N}$, i.e. $\beta=P I F E<0$.

- $\quad$ Case 2-A) $r_{E}>\alpha>r_{N}$, i.e. $\beta^{\prime}>\beta$.

The price of the selling resource increases with time if the initial price $p_{S 0}$ is $p_{S O} \geq p^{* *}>{ }_{S O}{ }_{S 0}$, i.e. greater or equal than CIPES $>C I P S$, or $p^{* *}{ }_{S 0}>p^{*} S 0$.

- Case 2-B) $r_{E}>\alpha>r_{N}$, i.e. $\beta^{\prime}>\beta$.

The price of the selling resource decreases temporarily with time up to $t_{m}$, given by Eq. (19), and then increases if the initial price, $p_{S O}$, has a value comprised between CIPS and CIPES, i.e. $p_{S O}^{*}>p_{S 0}>p *_{S O}^{*}>0$.

- $\quad$ Case 2-C) $\alpha>r_{N}$, i.e. $\beta<0$.

In all other cases the price of the selling resource decreases with time, which include $r_{E}=\alpha>r_{N}$, or $\alpha>r_{N}>r_{E}$, or $\alpha>r_{N}>r_{E}$

Category $3-\alpha=r_{N}$, i.e. $\beta=P I F E=0$.

- Case 3-A) $r_{E}>r_{N}=\alpha$, i.e. $\beta>\beta=0$.

The price of the selling resource increases with time if the initial price $p_{S O}$ is $p_{S O}>p^{* *}{ }_{S O}=p^{*}$ so, i.e. greater than CIPS $=$ CIPES, $p^{* *} S O=p^{*} S O$.

- Case 3-B) $r_{E}>r_{N}=\alpha$, i.e. $\beta^{\prime}>\beta=0$.

The price of the selling resource remains constant with time if the initial price $p_{S 0}$ is $p_{S 0=p^{*} *_{S 0}=}$ $p^{*}$ so, i.e. equal to $C I P S=C I P E S, p^{* *}{ }_{S O}=p^{*}{ }_{S O}$.

- Case 3-C) $r_{E}>r_{N}=\alpha$, i.e. $\beta^{\prime}>\beta=0$, or $r_{N}=\alpha>r_{E}$, i.e. $\beta^{\prime}<\beta=0$. 
The price of the selling resource, for $r_{E}>r_{N}=\alpha$, decreases with time if the initial price $p_{S 0}$ is $p_{S 0}<$ $p^{* *}{ }_{S 0}=p^{*}$, i.e. smaller than CIPS $=C I P E S, p^{* *}{ }_{S 0}=p^{*}{ }_{s 0}$. In the other cases the price of the selling resource decreases with time for every value of $p_{S O}$.

Category $4-r_{N}=r_{E}$, i.e. $\beta^{\prime}=\beta$.

- $\quad$ Case 4-B) $r_{N}=r_{E}>\alpha$, i.e. $\beta^{\prime}=\beta>0$.

The price of the selling resource increases temporarily with time up to $t_{m}$, given by Eq. (2), and then decreases if the initial price $p_{S 0}$ is $p_{S O}>p^{* *}{ }_{S O}>0$, i.e. greater than CIPES $>0$.

- Case 4-C) $r_{N}=r_{E}>\alpha$, i.e. $\beta^{\prime}=\beta>0$, or $r_{N}=r_{E}<\alpha$, i.e. $\beta^{\prime}=\beta<0$, or $r_{N}=r_{E}=\alpha$, i.e. $\beta^{\prime}=\beta=0$. The price of the selling resource decreases with time if the initial price $p_{S 0}$ is $p^{* *}{ }_{S 0} \geq p_{S 0}>0$, i.e. equal or smaller than $C I P E S>0$. In all the other cases the price of the selling resource decreases with time for every value of $p_{S O}$.

A new category of cases has been introduced in [9], and is relative to the negative inflation rate, $r_{N}<0$, which has been registered from March to October 2009, i.e. after the economic crisis of 2008 [17]. This new category is interesting because the Hotelling rule forecasts a decrease of the oil price if the interest rate is assumed equal to the inflation rate, i.e. negative, while the conclusions of the present approach are different.

\section{Category $5-r_{N}<0$}

- $\quad$ Case 5-A) $r_{E}>\alpha>0>r_{N}$, i.e. $\beta^{\prime}>0>\beta$.

The price of the selling resource increases with time for every value of the initial price $p_{S O}$ because $p_{S 0}>0>p^{*}{ }_{S O}>p^{* *}$, since CIPS and CIPES are negative, or $0>p *_{S O}>p^{* *}{ }_{S 0}$.

- Case 5-B) $\alpha>r_{E}>0>r_{N}$, i.e. $0>\beta>\beta$.

The price of the selling resource increases temporarily with time up to $t_{m}$ and then decreases if the initial price, $p_{S 0}$, is $p^{* *}{ }_{S O}>p_{S O}>0>p^{*}$, i.e. smaller than CIPES $>0>C I P S$.

- Case 5-C) $\alpha>r_{E}>0>r_{N}$, i.e. $0>\beta>\beta$.

The price of the selling resource decreases with time if the initial price, $p_{S 0}$, is $p_{S 0}>p^{* *}{ }_{S 0}>$ $0>p^{*}$ So. , i.e. greater than CIPES $>0>C I P S$.

\section{FORECAST OF THE MONTHLY OIL PRICE}

The monthly oil price is forecasted according to Eq. 16, assuming the prime or the discount rate as $r_{E}$, the inflation rate as $r_{N}$ and the monthly extraction rate as $\alpha$. Figure 7 reports the real oil prices and the forecasts from January 1994 until October 2012 assuming the relation $p_{E 0}=p_{S O}$. It can be recalled that the assumption $p_{E 0}=p_{S O}$ means that the initial price of the extracted oil is equal to the initial price of the selling oil. The oil price predicted according to Eq. 16 is not directly dependent on the assumption about $p_{E O}$ but only on $p_{S O}$ and $p^{*}$. The initial price of the selling oil, 
$p_{S 0}$, and its relation with $p^{*}{ }_{S O}$ and $p^{* *}$, determines the forecast according to the category and the case.

The forecast with the prime or the discount rate of Fig. 7 at each month must be interpreted as the price obtained by the present approach at the same month. The forecast is made assuming the real oil price of each month as the initial price of the selling oil, $p_{S 0}$, and the oil and the economic data of each month, i.e. extraction and interest rates, to determine the parameters introduced by the present approach, i.e. the "Price Increase Factor of Extracted resources", PIFE, or $\beta$, as given by Eq. 10, the "Price Increase Factor of Sold resources", PIFS, or $\beta$ ', as given by Eq. 17, the "Critical Initial Price of Sold resources", CIPS, or $p^{*}$ s0, according to Eq. 18, and the "Critical Initial Price Extreme of Sold resources", CIPES, i.e. $p^{* *} s 0$, according to Eq. 20.

The predictions with the prime rate of Fig. 7 are generally greater than the real oil price with differences which are bigger from 1994 to 1997, during 2001, and from 2006 until 2008. The predictions with the discount rate of Fig. 7 are in better agreement with the real oil price from 1994 until 2005, while the differences are greater from 2006 until 2008. It is interesting to observe that the predictions are oscillating around the real prices from 2008 until October 2012.

It is now interesting to visualize the predictions within shorter periods of time, which are selected according to the relations among the interest rate, $r_{E}$, the inflation rate, $r_{N}$, and the extraction rate, $\alpha$. The time period from 1994 until October 2012 is divided into four smaller periods: 1994 to 2001, 2002 to 2005, 2006 to 2008, 2009 until October 2012.

Figure 8 reports the real oil price evolution from 1994 until 2001, where is evident that the oil price increased, also with some oscillations, from 1994 until January 1997, decreased from 1997 until 1998, again increased from 1999 until October 2000, and finally decreased from November 2000 until 2001.

Figure 8 reports also the price forecast from 1994 until 2001, which is a period when the prime and the discount rates were greater than the inflation and the extraction rates, i.e. $r_{E}>r_{N}>\alpha$. The forecasts are generally under the category 1, with the exceptions of January 1998 and July 1999, which are under the category 2, i.e. $r_{E}>\alpha>r_{N}$.

The predictions with the prime rate, reported in Fig. 8 for $p_{E 0}=p_{S 0}$, are to increase according to the category 1-A from 1994 until 2001, with the exceptions of January 1998 and July 1999 when the increase is under the category 2-A, and May 2001 under the category 1-B. The predictions to increase are due to the high values of the prime interest rates.

The predictions with the discount rate, reported in Fig. 8 for $p_{E 0}=p_{S 0}$, are the followings. During 1994 the forecast is a very small increase according to the category 1-B, with the exceptions of September 1994, when the prediction is to decrease under the category 1-B. During 1995 the 
forecast is to increase under the category 1-B, and 1-A in August and September. The forecast is to increase in 1996 under the category 1-B; to increase in 1997 under the category 1-B from January to April and 1-A from May to December; to increase in 1998 under the category 1-A, except in January under 2-A; to increase in 1999 under the category 1-A or 1-B, except in July under 2-A; to increase in 2000 and in the first middle of 2001 under the category 1-B. The prediction to increase is again due to the high values of the discount rate compared to the inflation rate. The forecast changes in 2001 when the discount rate becomes comparable to the inflation rate from July to September 2001, and smaller than the inflation rate from October to December 2001. The forecasts are to decrease in July, August, October and November under 1-B and 1-C.

The comparison between the forecasts with the prime or the discount rate shows that the assumption of the prime rate as $r_{E}$ is very optimistic, because from 1994 until 2001 the prime rate was quite high. The assumption of the discount rate as $r_{E}$ provides more realistic forecasts, which are closer to the real oil price evoluion, with some differences during the period. For example the forecasts are quite good during 1994 and 2001.

Figure 9 reports the real oil price evolution from January 2002 until January 2006, which has, despite some oscillations, a continuous increase. In this period the prime rates are greater than the inflation and the extraction rates, i.e. $r_{E}>r_{N}>\alpha$, while the discount rates are greater or smaller than the inflation and extraction rate, i.e. $r_{E}>r_{N}>\alpha$, or $r_{N}>r_{E}>\alpha$ or $r_{N}>\alpha>r_{E}$.

The forecasts with the prime rate, reported in Fig. 9 for $p_{E 0}=p_{S 0}$, are the followings. During 2002 the forecast is to increase according to the category 1-A, except in November and December under category 1-B. During 2003 the forecasts are to increase according to the category 1-B, except in November and December under category 1-A, and to decrease in February 2003, under the category 1-C. The forecasts during 2004 are to increase under 1-A and 1-B from January to May, to decrease under 1-C in June; to increase under 1-B from July to December. During 2005 the forecasts are to increase from January to April and from July to October under 1-B, and in May, June, November and December under 1-A.

The forecasts with the discount rate, reported in Fig. 9 for $p_{E 0}=p_{S 0}$, are the followings. During 2002 the forecasts are to increase under the category 1-B in January, April, June and December, but to decrease under 1-C in February and May, from July to November, and under 1-B in March. During 2003 the forecasts are to decrease under 1-C from January to March and from July to December, and to increase under 1-B from April to June. The forecasts during 2004 are to increase under 1-B from January to March and in August, to decrease under 1-C from April to July and from September to November, and under 1-B in December. During 2005 the forecasts are to decrease from January to March under 1-B and in April under 1-C, to increase from May to July 
under 1-B, to decrease under 1-B from August to October, and to increase under 1-B in November and December.

Figure 10 reports the real oil price evolution from January 2006 until January 2009. It is visible a decrease during the first months of 2006 and then an increase up the middle of 2006, followed by a decrease until January 2007. From January 2007 it is present a continuous increase up to June 2008 , followed by a drastic decrease until the end of 2008.

Figure 10 reports also the forecasts from 2006 until the end of 2008, which is a period when the prime rate is greater than the inflation and the extraction rates, i.e. $r_{E}>r_{N}>\alpha$, except from June to August 2008, when $r_{N}>r_{E}>\alpha$, while the discount rate is greater than the inflation and the extraction rate in 2006 and 2007, i.e. $r_{E}>r_{N}>\alpha$. During 2008, the discount rates are greater than the inflation and the extraction rates in January, November and December, i.e. $r_{N}>r_{E}>\alpha$, the inflation rates are greater than the discount and the extraction rates from February to September, i.e. $r_{N}>r_{E}>\alpha$, and the inflation rate is greater than the extraction and the discount rate in October, i.e. $r_{N}>\alpha>r_{E}$.

The forecasts with the prime rate, reported in Fig. 10 for $p_{E 0}=p_{S 0}$, are the followings. From January 2006 until April 2008 the predictions are to increase according to the category 1-A and 1-B, to decrease from May to August 2008 and in October 2008 under 1-B and 1-C, and to increase in November and December 2008 under 1-A.

The predictions with the discount rate, reported in Fig. 10 for $p_{E 0}=p_{S 0}$, are the followings. From January 2006 until November 2007 the predictions are to increase according to the category 1-B or 1-A, to decrease from December 2007 until October 2008 under the category 1-B and 1-C, and to increase under 1-B and 1-A in November and December 2008.

Figure 11 reports the real oil price evolution from January 2009 until January 2013. It is visible, despite some oscillations, an increase from January 2009 to April 2010, followed by a decrease and a constant period until August 2010, and an increase up to April 2011. From May 2011 the real oil price is oscillating with a minimum during the summer of 2011, a maximum in March 2012 and other oscillations up to January 2013.

The real economic data of this period are the followings. During 2009 the prime rate is greater than the inflation and the extraction rates, i.e. $r_{E}>r_{N}>\alpha$, in January, November and December; the prime rate is greater than the extraction and the inflation rates, i.e. $r_{E}>\alpha>r_{N}$, in February, while the inflation rate is negative, i.e. $r_{E}>\alpha>0>r_{N}$, from March to October. During 2010 and 2012 the prime rate is greater than the inflation and the extraction rates, i.e. $r_{E}>r_{N}>\alpha$, while during 2011 the prime rate is greater than the inflation and the extraction rates from January until April and in December, i.e. $r_{E}>r_{N}>\alpha$, but the inflation rate is greater than the prime rate and the extraction rate from May until November, $r_{N}>r_{E}>\alpha$. 
The relations among the extraction and the economic rates are more complicated as far as the discount rate is concerned. During 2009 the discount rate is greater than the inflation and the extraction rates, i.e. $r_{E}>r_{N}>\alpha$, only in January, while in February, July, September and October the extraction rate is greater than the discount and the inflation rates, i.e. $\alpha>r_{E}>r_{N}$. From March to June 2009 and in August 2009 the discount rate is greater than the extraction and the inflation rates, i.e. $r_{E}>\alpha>0>r_{N}$, and finally the inflation rate is greater than the discount and the extraction rates in November and December, i.e. $r_{N}>r_{E}>\alpha$. From January 2010 until October 2012 the inflation rate is generally greater than the discount or the extraction rates, i.e. $r_{N}>r_{E}>\alpha$, except in February and November 2010, in June, August, October and November 2011, and in October 2012, when $r_{N}>\alpha>r_{N}$

The predictions with the prime rate, reported in Fig. 11 for $p_{E 0}=p_{S 0}$, are the followings. During 2009 the forecast is to increase according to the category 1-A in January, 2-A in February, 5-A from March to October, and 1-B in November and December. During 2010 the forecasts are to increase slightly under the category 1-B from January until May, and to increase under 1-A in the rest of the year. The forecasts are to increase from January to March 2011 under 1-B, to decrease from April 2011 to February 2012 under 1-B and 1-C. From March 2012 until October 2012 the forecasts are to increase under 1-B and 1-A.

The predictions with the discount rate, reported in Fig. 11 for $p_{E 0}=p_{S 0}$, are the followings. The forecasts are to increase according to the category 1-A in January 2009, according to 5-A and 5-B from March to October 2009, and to decrease under 2-C in February 2009 and 1-C in November and December 2009. From January 2010 until October 2012 the forecasts are to decrease under the category $1-\mathrm{C}$.

\section{CONCLUSIONS}

The paper extends the method of using the mass and the energy-capital conservation equations to forecast the monthly oil price from 1994 until October 2012. The present theory assumes the inflation rate as the interest rate of the non-extracted oil, the prime or the discount rate as the interest rate of the selling oil. The introduction of the extraction rate of oil into the mass and energy conservation equations allow to define four parameters which are important in the evaluation of the forecast. The general conclusion is that with high values of the prime rate the forecast is generally an increase, due to the optimistic assumption of a high interest rate of the selling oil, while a smaller value of the discount rate brings to a more realistic forecast. It is interesting to observe that in several years the use of the two interest rates can provide the extremes limits of the forecast. 


\section{References}

[1] H. Hotelling, The Economics of Exhaustible Resources, Journal of Political Economy, 39 (1931) 137-175.

[2] P.S. Dasgupta, G.M. Heal, Economic Theory and Exhaustible Resources, Cambridge University Press, 1979.

[3] F. Gori, Mass and Energy-Capital Conservation Equations to Study the Price Evolution of nonRenewable Energy Resources. Part I-Generalization of the Hotelling Rule, Applied Thermal Engineering, 26 (2006) 1746-1750.

[4] F. Gori, Mass and Energy-Capital Conservation Equations to Study the Price Evolution of nonRenewable Energy Resources. Part II -Extension to resources sold to the market, Applied Thermal Engineering, 26 (2006) 1751-1770.

[5] F. Gori, Mass and Energy-Capital Conservation Equations to Study the Price Evolution of NonRenewable Energy Resources. Part III-Energy supply curve, Applied Thermal Engineering, 29 (2009) 2172-2186.

[6] F. Gori, Mass and Energy-Capital Conservation Equations for the Time Evolution of NonRenewable Energy Resources, in: J. Evgova, O. Kostadinov, (Eds.), Thermal Engineering Research Developments, Nova Science Publishers Inc., New York, 2009, Chapter 5.

[7] www.bp.com/statisticalreview.

[8] F. Gori, Forecasting the Time Evolution of Oil Price with Negative Inflation Rate, in: Proceedings of ASME 2012 International Mechanical Engineering Conference and Exhibition, November 9-15, Houston, Texas, USA, 2012, Paper 86729.

[9] F. Gori, Forecasting the Time Evolution of the Oil Price During Months of Negative Inflation Rate, Journal of Energy Resources Technology, 135/1 (2013), 011602 (8 pages), ISSN 0195-0738 (print), 1528-8994 (online), http://dx.doi.org/10.1115/1.4007912.

[10]

http://www.eia.gov/cfapps/ipdbproject/iedindex3.cfm?tid=5\&pid=53\&aid=1\&cid=ww,\&syid=1994 $\underline{\text { \&eyid }=2011 \& \text { unit }=\text { TBPD }}$

[11] www.economagic.com/em-cgi/data.exe

[12] http://inflationdata.com/Inflation/Inflation_Rate/HistoricalInflation.aspx

[13] M. Tenenbaum, H. Pollard, Ordinary Differential Equations, Dover Pub. Inc., New York, 1963. 


\section{CAPTIONS TO FIGURES.}

Figure 1. Annual mass flow rate of oil extraction, G (MT/year), versus year.

Figure 2- Extraction rate $\alpha(\% /$ annum $)$ and critical extraction rate $\alpha_{c}(\% /$ annum) of oil versus year.

Figure 3. Evolution of the proved reserves of oil, M (M T), versus year.

Figure 4. Evolution of M/G (years) of oil versus year.

Figure 5 - Monthly mass flow rates of extracted oil, G, (MT/year), in the world, [10].

Figure 6 - Monthly oil price (US\$ day/GJ) and inflation rate (\%/annum).

Figure 7 - Monthly oil price forecasted with prime or discount rate from 1994 until October 2012.

Figure 8-Monthly oil price forecasted with prime or discount rate from 1994 until 2001.

Figure 9 - Monthly oil price forecasted with prime or discount rate 2002 until 2005.

Figure 10 - Monthly oil price forecasted with prime or discount rate from 2006 until 2008.

Figure 11 - Monthly oil price forecasted with prime or discount rate from 2009 until October 2012. 


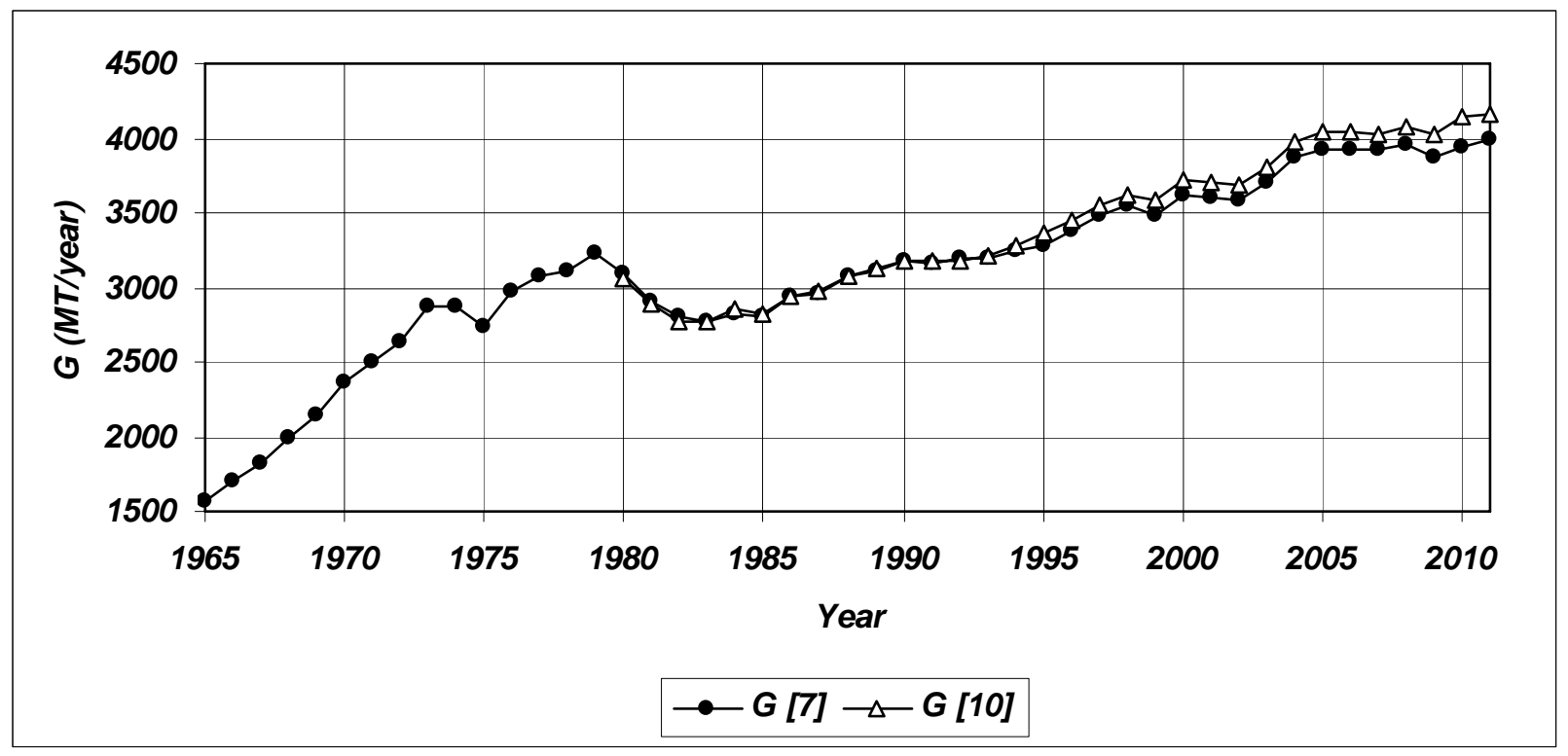

Figure 1. Annual mass flow rate of oil extraction, G (MT/year), versus year. 


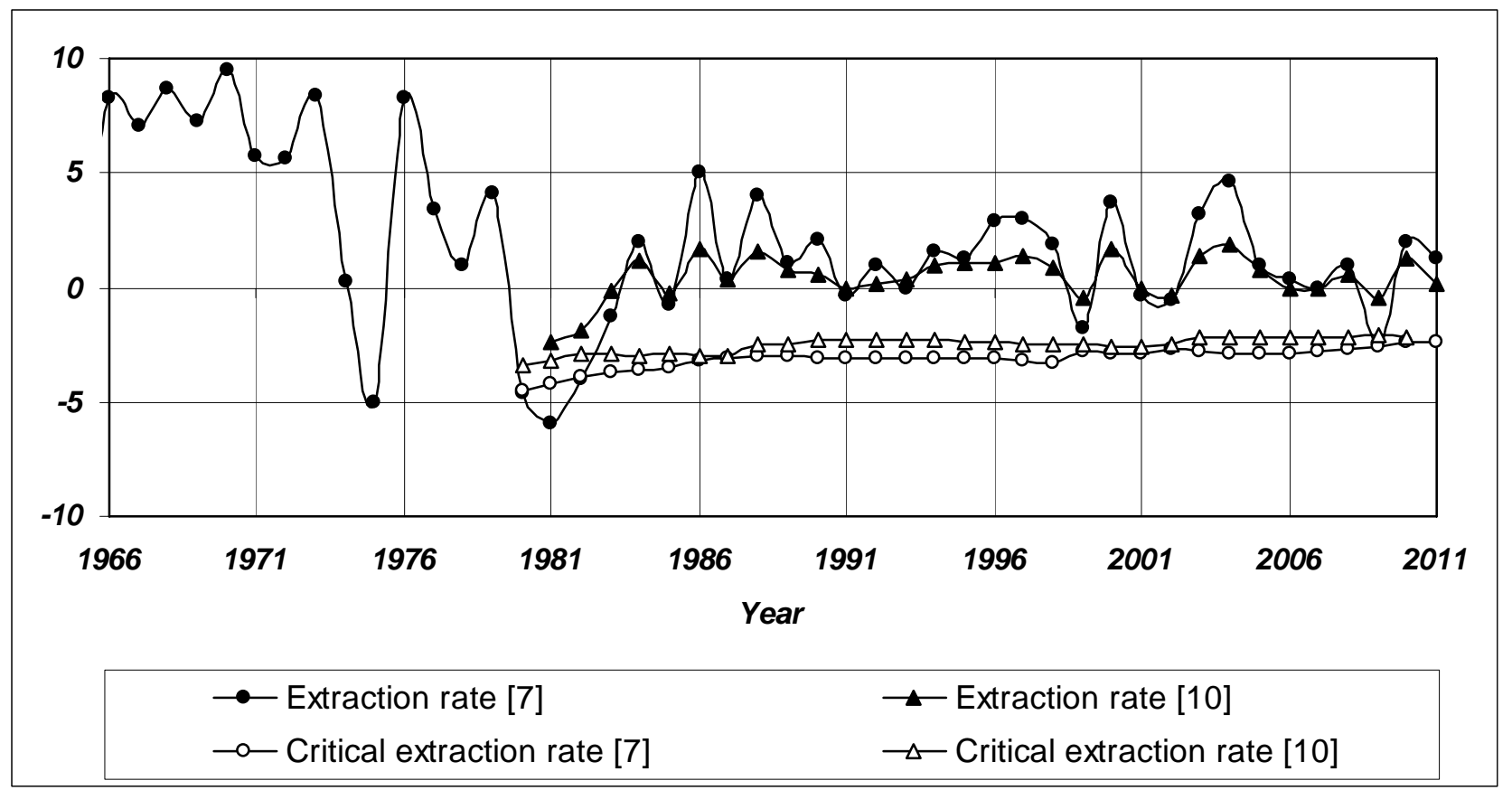

Figure 2- Extraction rate $\alpha(\% /$ annum $)$ and critical extraction rate $\alpha_{c}(\% /$ annum $)$ of oil versus year. 


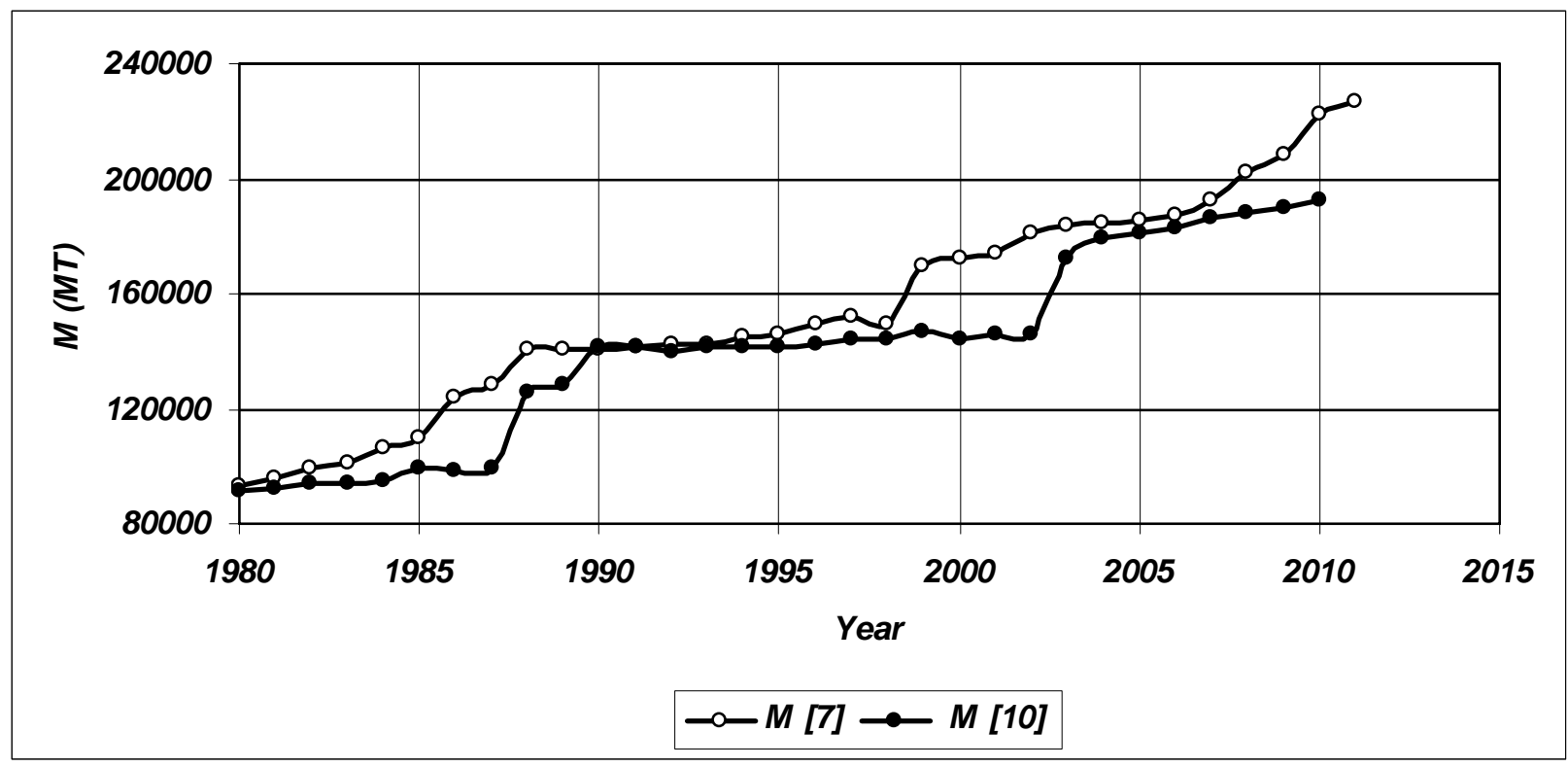

Figure 3. Evolution of the proved reserves of oil, M (M T), versus year. 


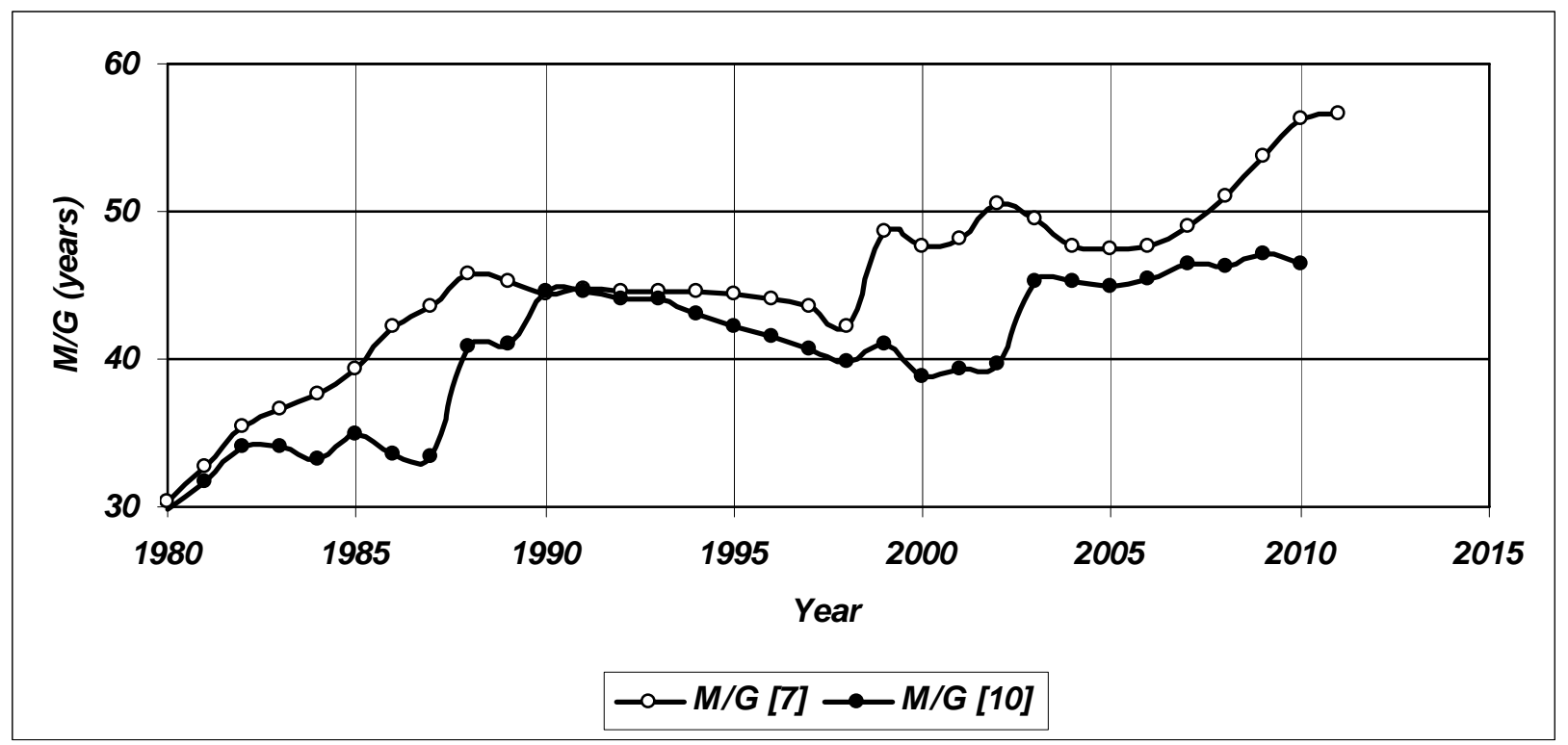

Figure 4. Evolution of M/G (years) of oil versus year. 


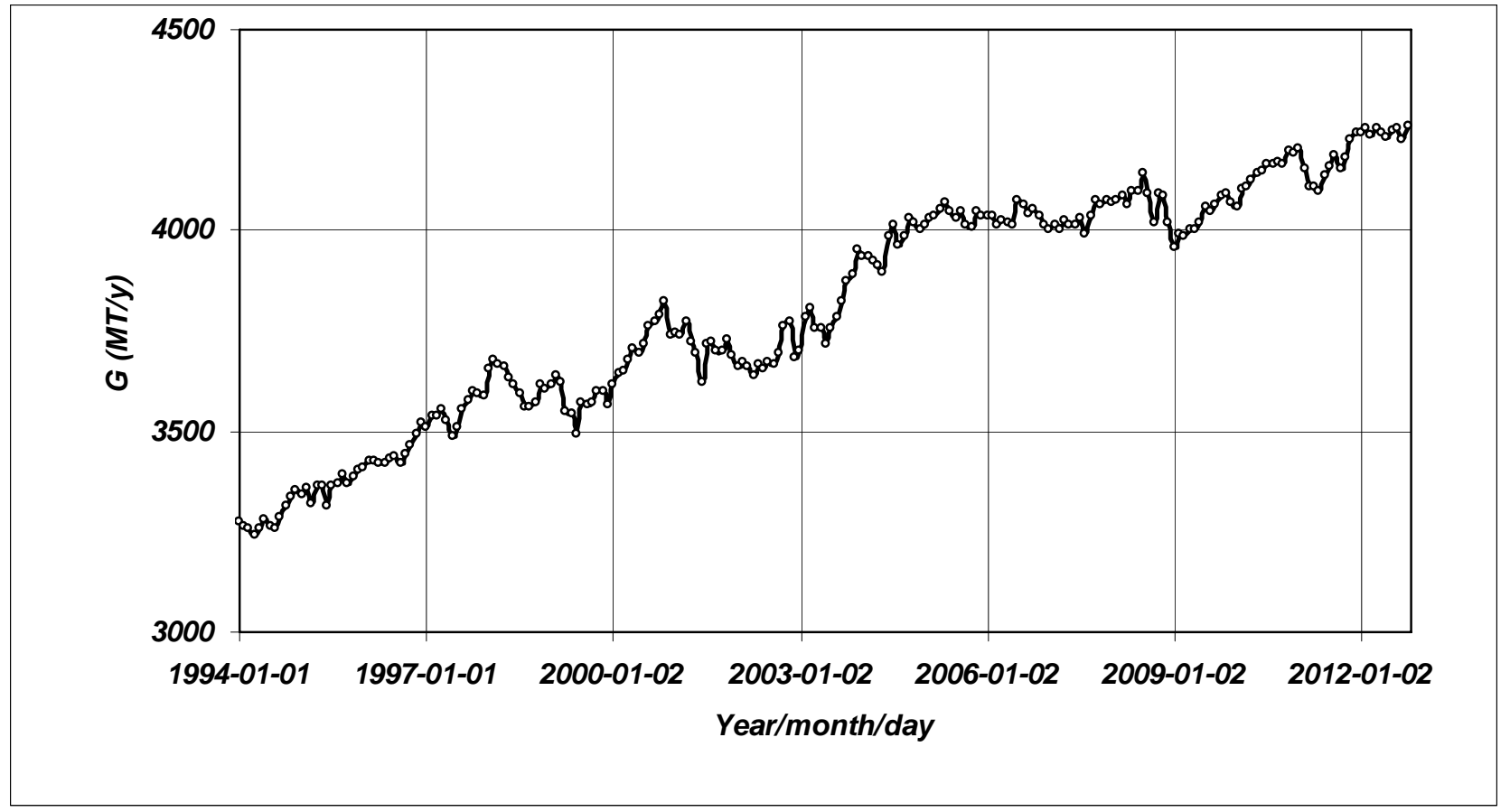

Figure 5 - Monthly mass flow rates of extracted oil, G, (MT/year), in the world, [10]. 


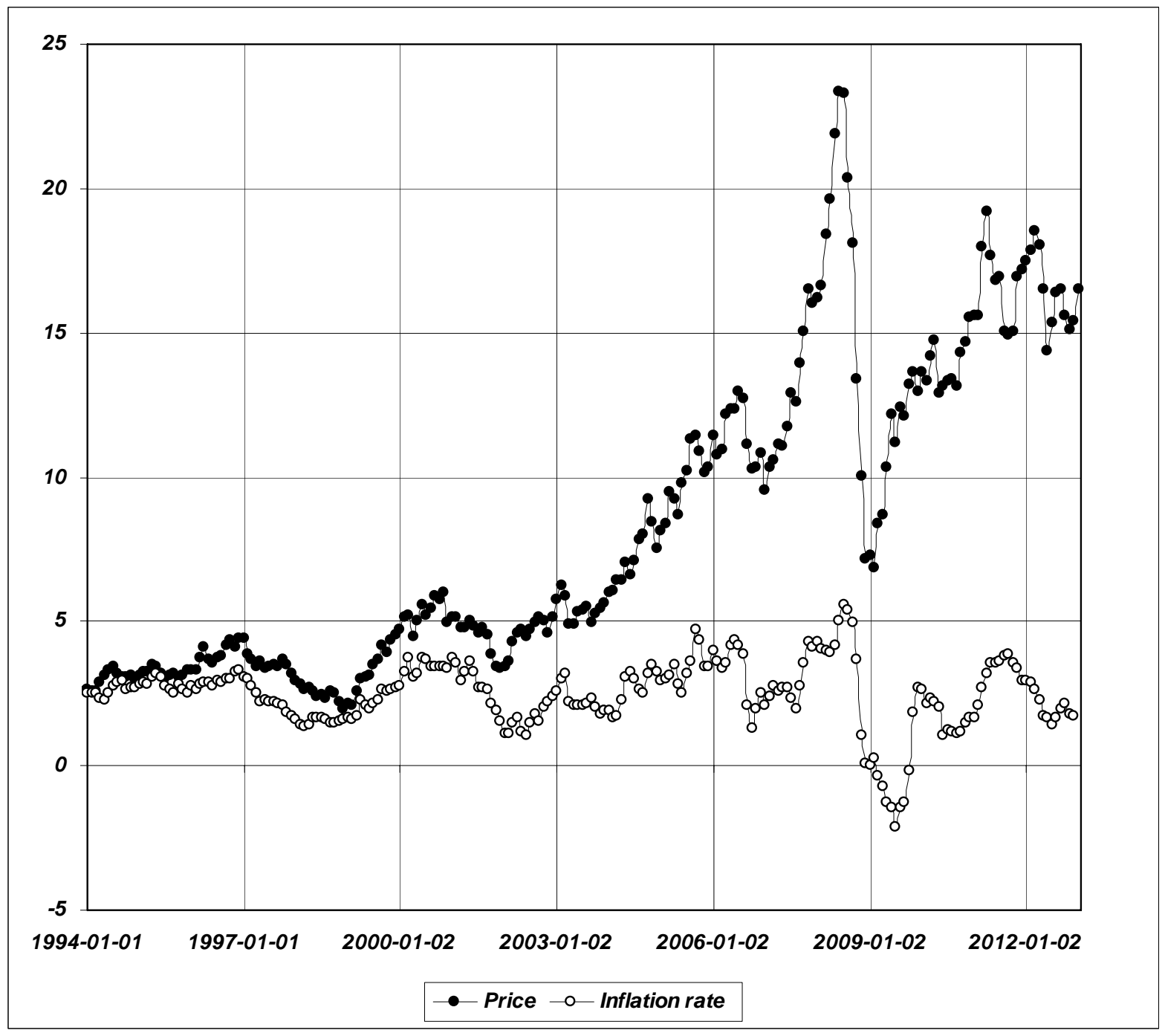

Figure 6 - Monthly oil price (US\$ day/GJ) and inflation rate (\%/annum). 


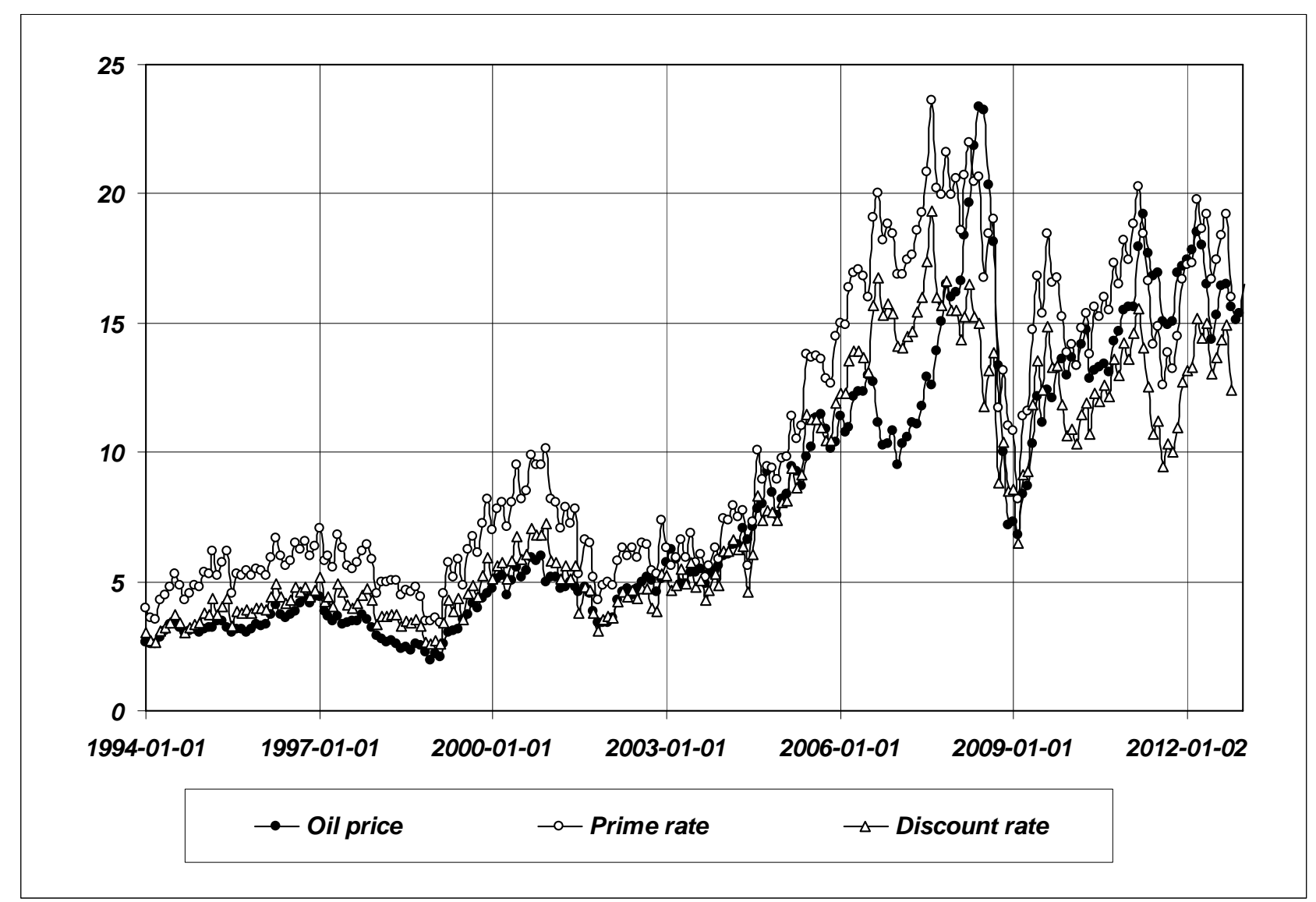

Figure 7 - Monthly oil price forecasted with prime or discount rate from 1994 until October 2012. 


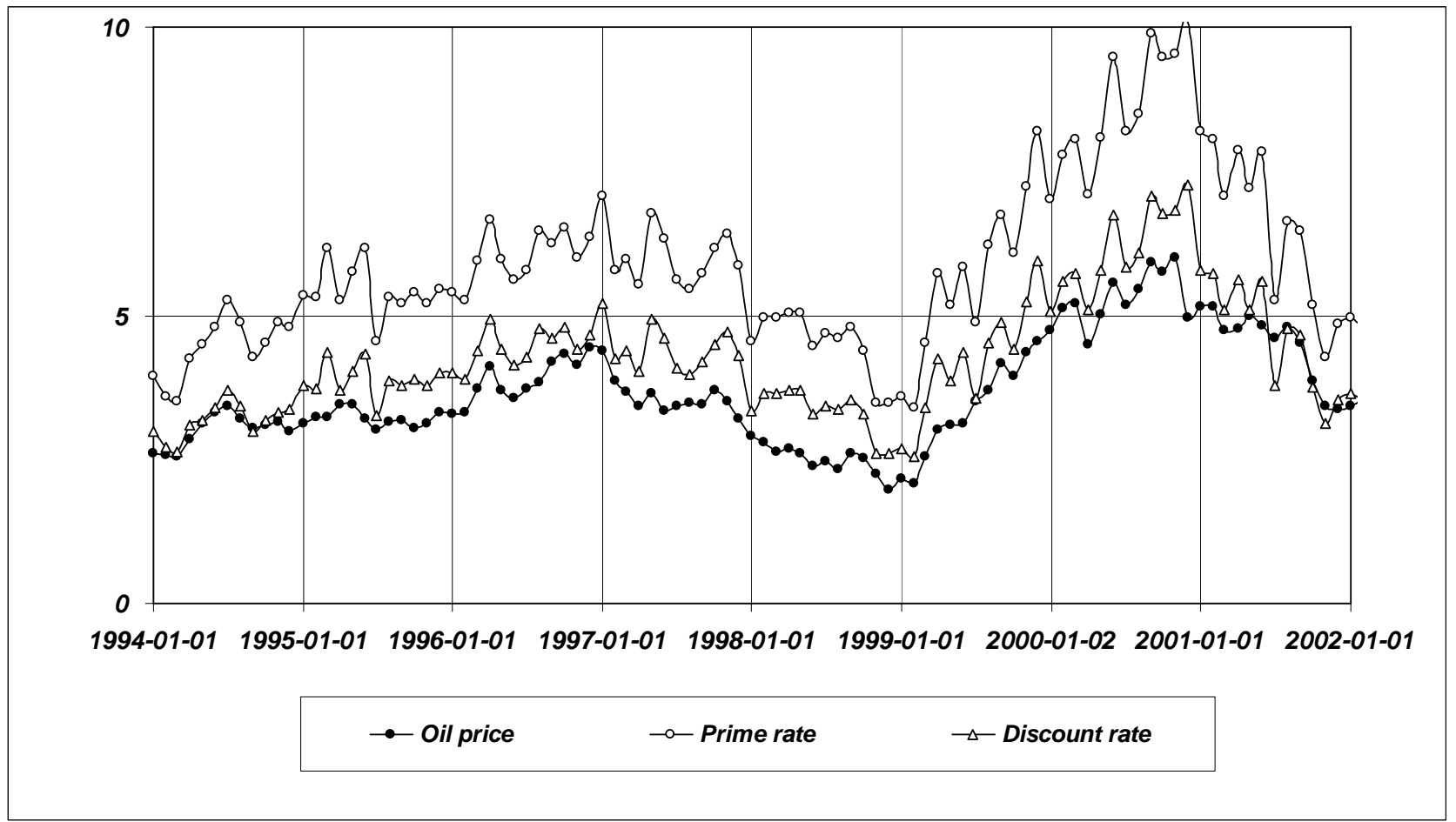

Figure 8-Monthly oil price forecasted with prime or discount rate from 1994 until 2001. 


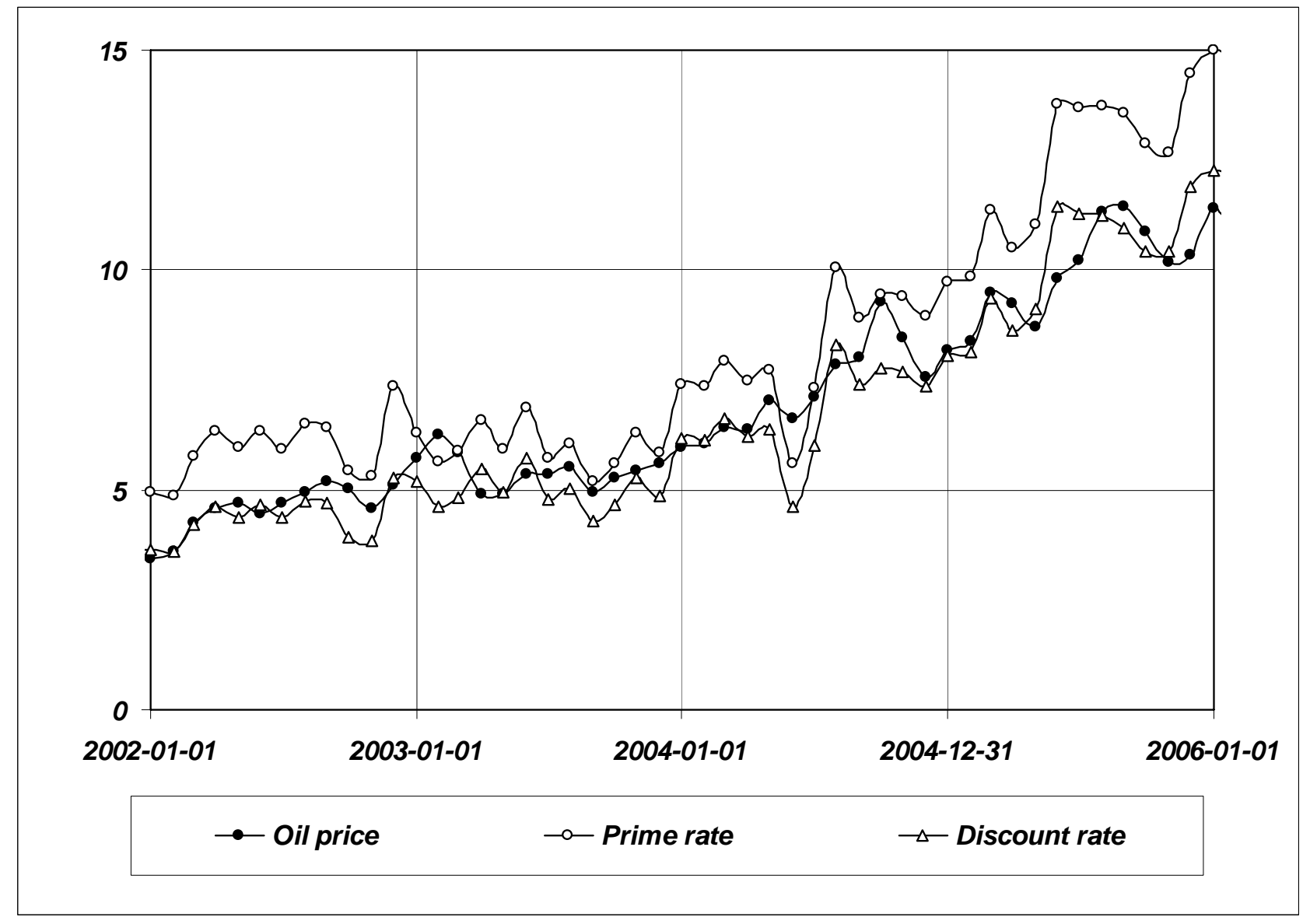

Figure 9 - Monthly oil price forecasted with prime or discount rate 2002 to 2005 . 


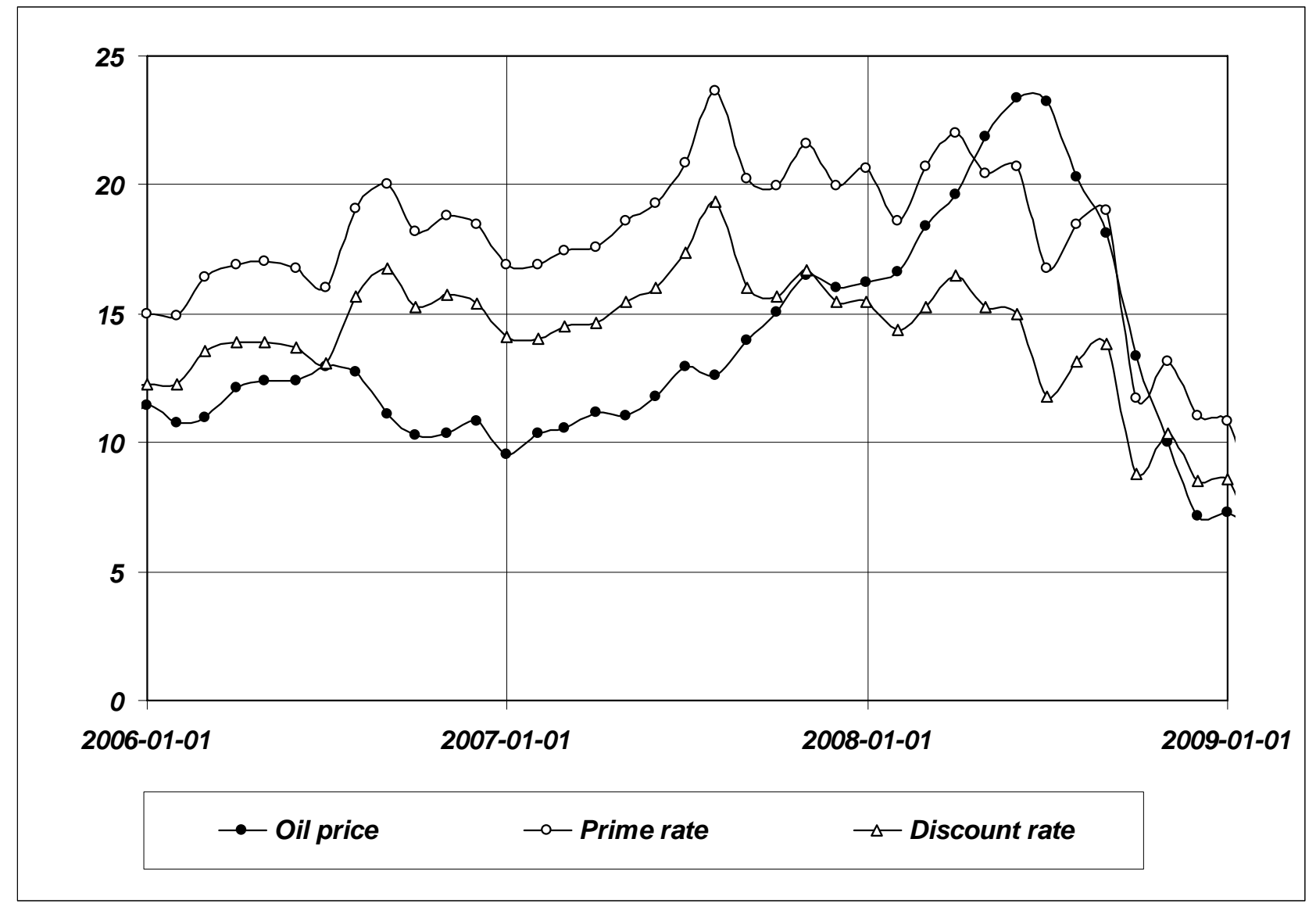

Figure 10 - Monthly oil price forecasted with prime or discount rate from 2006 until 2008. 


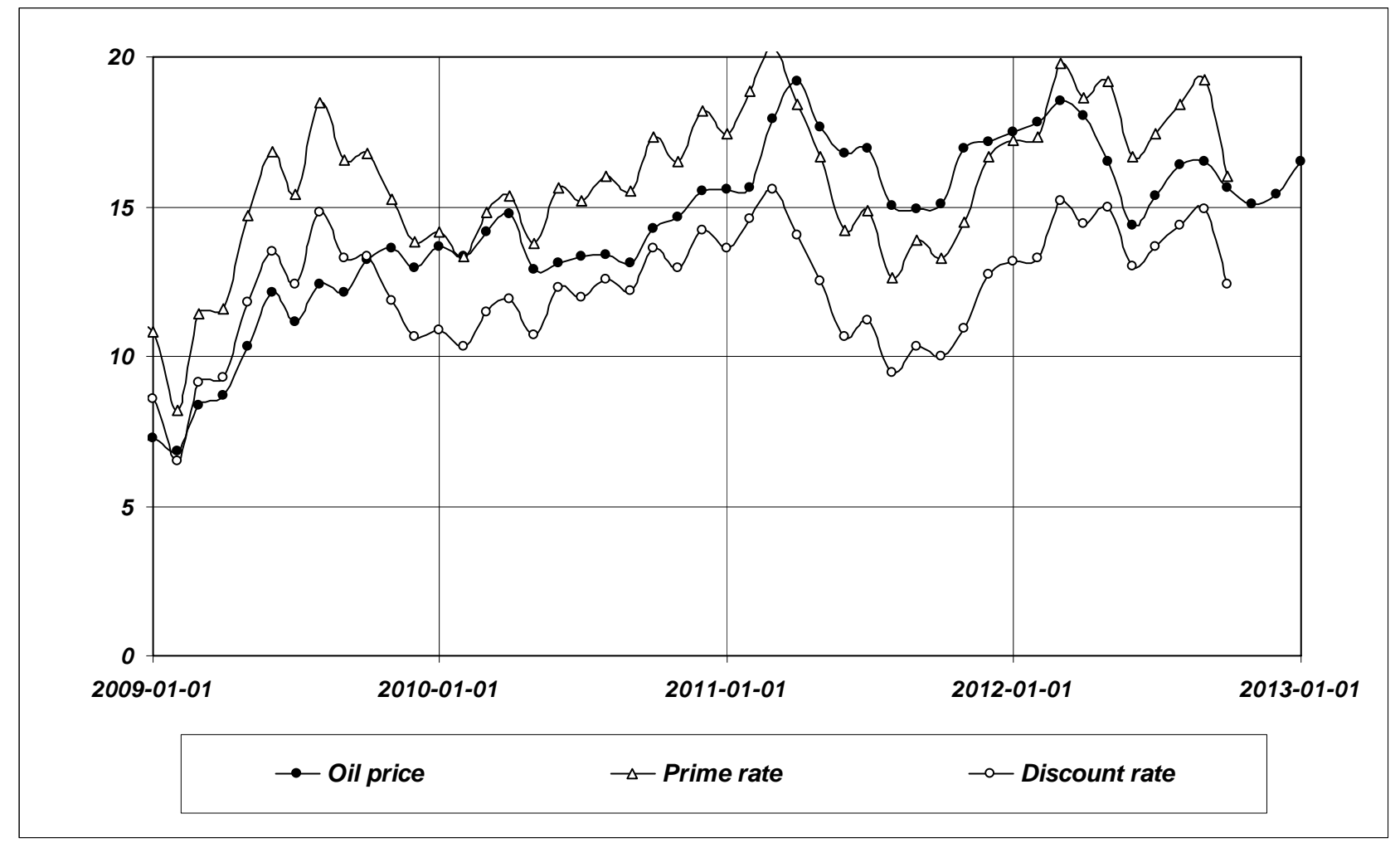

Figure 11 - Monthly oil price forecasted with prime or discount rate from 2009 until October 2012. 